\title{
The application of backpropagation neural network method to estimate the sediment loads
}

\author{
Taufik Ari Gunawan ${ }^{1, *}$, M. Syahril Badri Kusuma ${ }^{2}$, M. Cahyono ${ }^{2}$, Joko Nugroho $^{2}$ \\ ${ }^{1}$ Civil Engineering Departement, Faculty of Civil and Environmental Engineering, ITB, 40132 Bandung, Indonesia \\ ${ }^{2}$ Water Resources Development Center, Bandung Institute of Technology, 40132 Bandung, Indonesia
}

\begin{abstract}
Nearly all formulations of conventional sediment load estimation method were developed based on a review of laboratory data or data field. This approach is generally limited by local so it is only suitable for a particular river typology. From previous studies, the amount of sediment load tends to be non-linear with respect to the hydraulic parameters and parameter that accompanies sediment. The dominant parameter is turbulence, whereas turbulence flow velocity vector direction of $\mathrm{x}, \mathrm{y}$ and $\mathrm{z}$. They were affected by water bodies in 3D morphology of the cross section of the vertical and horizontal. This study is conducted to address the non-linear nature of the hydraulic parameter data and sediment parameter against sediment load data by applying the artificial neural network (ANN) method. The method used is the backpropagation neural network (BPNN) schema. This scheme used for projecting the sediment load from the hydraulic parameter data and sediment parameters that used in the conventional estimation of sediment load. The results showed that the BPNN model performs reasonably well on the conventional calculation, indicated by the stability of correlation coefficient (R) and the mean square error (MSE).
\end{abstract}

\section{Introduction}

A number of researchers across the globe have developed various procedures and theory to predict sediment load. Formulations of bed load were first developed and introduced extensively by $\mathrm{Du}$ Boys (1879) with the concept of shear stress approach [1]. Furthermore, several approaches were developed such as graphics solution, the concept of probability, stream power concepts and the methods of multimodal characteristics. The method that most frequently used by researchers is the regression method [2]. So far, the existing theories have not been able to accurately predict the actual sediment load when implemented on particular rivers [3]. From various measurement data test through the sediment flume experiments in the laboratory and natural river measurement data, there are limitations in the application of available theories [4]. The results show that there is a big difference between the rates of sediment transport estimation with the sediment discharge measurement results.

The development of the sediment load estimation formulation in the last decade has been developed by [5] for large rivers in terms of the universal stream power is compared with selected bed-material load equations using large and medium river data. The next development, total bed-material discharge in alluvial channels [6], a comparative study of some of the sediment transport equations for an alluvial channel with dunes [3], fractional transport of sediment mixtures [7] and sediment concentration prediction and statistical evaluation for annual load estimation [8] as well as some computer programs developed by [9] about comparison of sediment transport computations using hydrodynamic versus hydrologic models, estimating the sediment transport capacity using HEC-RAS [10] and software for evaluating sediment-induced stratification in open-channel flows [11]. Final conclusions indicate that these formulas generally remain localized, so that this method is only suitable for certain river typology and cannot be used for any random river.

The magnitude of sediment load tends to be nonlinear with respect to the hydraulic parameters and parameter accompanying sediment. The character of non-linear influenced by turbulence, where the turbulence flow velocity vector direction of $\mathrm{x}, \mathrm{y}$ and $\mathrm{z}$ are influenced by the morphology of the water body in 3D on the vertical cross section and horizontal [12]. Whilst, all sediment load estimation formulations does not take into account this and are usually very difficult to retrieve data relating to a third of the velocity vector.

The past few years, researchers chose an alternative approach by developing artificial neural network (ANN) models. In some cases, the ANN has proven to be a

\footnotetext{
* Corresponding author: tagz.unsrir@gmail.com
} 
better alternative for nonlinear modeling [13]. This is indicated by one of the features on ANN i.e. the ability to extract the relationship between input and output without reviewing the physical process. The network was able to do a mapping of the multivariate space with one another, even apply to a data set that contains errors. In some studies, ANN method is suitable to solve the problem of estimation and prediction on hydrology field [14].

The following applications in various calculations of ANN in sediment load or transport can be developed by [15] for prediction of suspended sediment using ANN GA conjunction model with Markov chain approach at flood conditions, combining deterministic modelling with ANN for suspended sediment estimates [16]; integrative neural networks model for prediction of sediment rating curve parameters for ungauged basins [17]; a review sediment load change [18]; stream flow discharge and sediment rate relation using ANN [19]; evaluation of transport formulas and ANN models to estimate suspended load transport rate [20]; daily suspended sediment load prediction using ANN and support vector machines [21]; estimate sediment load in ungauged catchments using ANN [22]; suspended sediment modeling using genetic programming and soft computing techniques [23]; estimation of daily suspended sediments using support vector machines [24] and prediction of bed material load transport using neural network [25].

This study aims to demonstrate the non-linear properties of the hydraulic parameters data and sediment parameter with the sediment load measurement data. This fact can be seen clearly on the calculation results by applying some conventional calculation method i.e. Yang method, Ackers and White method, Engelund and Hansen method, and Laursen method. The result of this conventional calculation will be compared with the results on the application of the backpropagation neural network (BPNN) schema. The sediment load of the hydraulic parameter data was projected with this schema. The stream data in the United States and data from laboratory testing were used for this purpose.

\section{Methodology}

In this study, a description of estimation methods only serves basic formulas and calculation results. Furthermore, the main focus is on the application of BPNN to estimate sediment load.

The study adopted a simple methodology to prove that the model BPNN are able to map the data inputoutput regardless of the physical processes that accompany it. Variable data are used as input data matrix and concentration measurement data sediment as a target matrix. Before conducting simulation model, the first data set is identified carefully, this is to avoid extreme values into the training process in order to produce a natural output. According to the rules in the modeling BPNN input data and targets for training as much as $80 \%$ and the remaining $20 \%$ is used for testing.
The advantages of BPNN is the use of the hidden layer algorithm. The function of hidden layers is to reduce the error output through the propagation control information errors on output layer unit to the hidden layer. This method is one way to optimize the neural network. The differences of hidden layer numbers are compared to obtain the optimal estimation. Variations in the amount of BPNN hidden layers scheme in the implementation of the MATLAB program application can be seen the figure 1 .

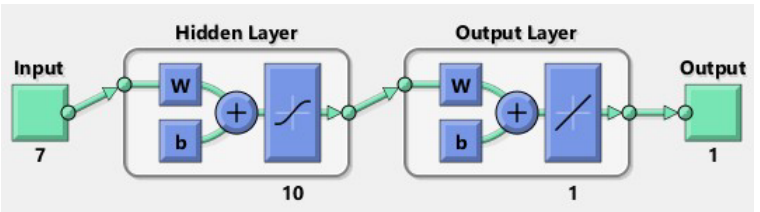

Fig. 1. Implementation hidden layer at BPNN schema

\section{Data collection}

In order to get the best results, a vast amounts of data are required. This study used 806 hydraulic and sediment data collected from 18 sets of laboratory data streams in the United States. This secondary data was obtained from the database of the Civil Engineering Department, Diponegoro University, Indonesia. The existing data set covering; name of the researchers, measurement date, water discharge $\left(Q_{w}\right)$, flow velocity $(V)$, flow depth $(h)$, channel width $(w)$, slope $(S)$, water temperature $(T)$, the mean bed diameter $\left(d_{s}\right)$ and the concentration of sediment load $\left(C_{m}\right)$. The concentration is converted to a form sediment load using the formula:

$$
q_{m}=\frac{Q_{w}}{w} C_{m} \times 10^{-3}
$$

Table 1. Data collection

\begin{tabular}{|c|c|}
\hline Researcher / Sources & $\begin{array}{c}\text { Number } \\
\text { of data }\end{array}$ \\
\hline Barton \& Lin (1955) & 30 \\
\hline Brooks (Vanoni \& Brooks, 1957) & 21 \\
\hline Franco (1968) & 19 \\
\hline Guy, Simons \& Richardson (1966) & 290 \\
\hline Kalinske \& Hsia (1945) & 9 \\
\hline Kennedy \& Brooks & 9 \\
\hline Laursen (1958) & 24 \\
\hline Meyer, Peter \& Muller (1948) & 55 \\
\hline Nomicos 1 (Toffaleti, 1968; Vanoni \& Brooks, 1957 & 12 \\
\hline Nomicos 2 (Vanoni \& Brooks, 1957) & 26 \\
\hline Onishi, Jain \& Kennedy (1976) & 14 \\
\hline Stein (1965) & 57 \\
\hline Straub (1954 \& 1958) & 24 \\
\hline Taylor \& Vanoni (1972) & 6 \\
\hline Vanoni \& Brooks (1957) & 15 \\
\hline Vanoni \& Hwang (1967) & 16 \\
\hline Williams (1970) & 83 \\
\hline Willis, Coleman \& Ellis (1972) & 96 \\
\hline Total data & $\mathbf{8 0 6}$ \\
\hline
\end{tabular}


Table 2. Statistics parameter data

\begin{tabular}{|c|c|c|c|c|}
\hline $\begin{array}{c}\text { Statistics } \\
\text { parameter }\end{array}$ & average & st-dev & minimum & maximum \\
\hline$Q_{w}\left[\mathrm{~m}^{3} / \mathrm{s}\right]$ & 0.31 & 0.67 & 0.003 & 4.614 \\
\hline$w[\mathrm{~m}]$ & 1.25 & 0.80 & 0.267 & 2.438 \\
\hline$h[\mathrm{~m}]$ & 0.19 & 0.14 & 0.027 & 1.092 \\
\hline$V[\mathrm{~m} / \mathrm{s}]$ & 0.83 & 0.50 & 0.188 & 2.879 \\
\hline$d_{s}[\mathrm{~mm}]$ & 1.72 & 5.71 & 0.011 & 28.65 \\
\hline$S_{w}[\mathrm{~m} / \mathrm{m}]$ & 0.00337 & 0.00369 & 0.00015 & 0.03310 \\
\hline$T\left[{ }^{\circ} \mathrm{C}\right]$ & 20.36 & 5.32 & 1.70 & 48.00 \\
\hline$C_{m}[\mathrm{ppm}]$ & 4198 & 10206 & 1 & 11099 \\
\hline$q_{m}[(\mathrm{~kg} / \mathrm{s}) / \mathrm{m}]$ & 0.82 & 1.88 & $4 \mathrm{E}-05$ & 18.33 \\
\hline
\end{tabular}

\section{Estimation using formulation methods}

In this study, the data were tested using a variety of estimation methods of total sediment load. The value of transport sediment concentration measurement data is the total value of the sediment load. This study limited to the use of 4 estimation of total sediment load methods that represents the concept of different formulation development. The relationship between the calculation parameter formula for each method, presented as follows :

A. Yang method (stream power's concept)

$$
\begin{aligned}
\log C_{t}= & 5.435-0.286 \log \frac{\omega d_{s}}{v}-0.457 \log \frac{u_{*}}{\omega} \\
& +\left(1.799-0.409 \log \frac{\omega d_{s}}{v}-0.314 \log \frac{u_{*}}{\omega}\right) \\
& \log \left(\frac{V \cdot S_{w}}{\omega}-\frac{V_{c r} \cdot S_{w}}{\omega}\right)
\end{aligned}
$$

B. Ackers and White Formula method (regresion's concept)

$$
C_{t}=\frac{G_{g r} d_{s}\left(\frac{\gamma_{s}}{\gamma}\right)}{h\left(\frac{u_{*}}{V}\right)^{n}} \cdot 10^{6}
$$

where:

$$
\begin{gathered}
F_{g r}=\frac{u_{*}{ }^{n}}{\left[g d_{s}\left(\frac{\gamma_{s}}{\gamma_{w}}-1\right)\right]^{1 / 2}}\left[\frac{V}{\sqrt{32} \log \left(\frac{\alpha h}{d_{s}}\right)}\right]^{1-n} \\
G_{g r}=C\left(\frac{F_{g r}}{A_{1}}-1\right)^{m}
\end{gathered}
$$

C. Engelund and Hansen method (stream power's concept)

$$
q_{t}=0.05 \gamma_{s} V^{2}\left[\frac{d_{50}}{g\left(\gamma_{s} / \gamma-1\right)}\right]^{1 / 2}\left[\frac{\tau_{0}}{\left(\gamma_{s}-\gamma\right) d_{50}}\right]^{3 / 2}
$$

D. Laursen method (stochastic's concept)

$$
C_{t}=0.01 \gamma\left(\frac{d_{s}}{h}\right)^{7 / 6}\left(\frac{\tau^{\prime}}{\tau_{c}}-1\right) f\left(\frac{u_{*}}{\omega_{i}}\right)
$$

The formulation is converted to a form sediment load using the formula:

$$
q_{t}=\gamma_{w} h V\left(C_{t} \times 10^{-6}\right)
$$

The final result of each method in the form of sediment load estimation is presented in Fig. 2 for the data distribution and Fig.3 for the comparison of measurement data.

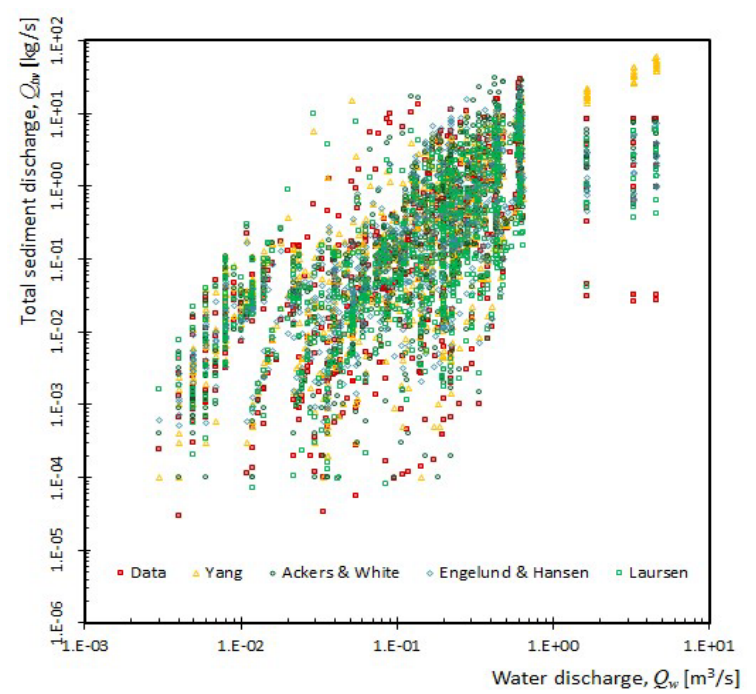

Fig. 2. The distribution of measurement data and calculation results

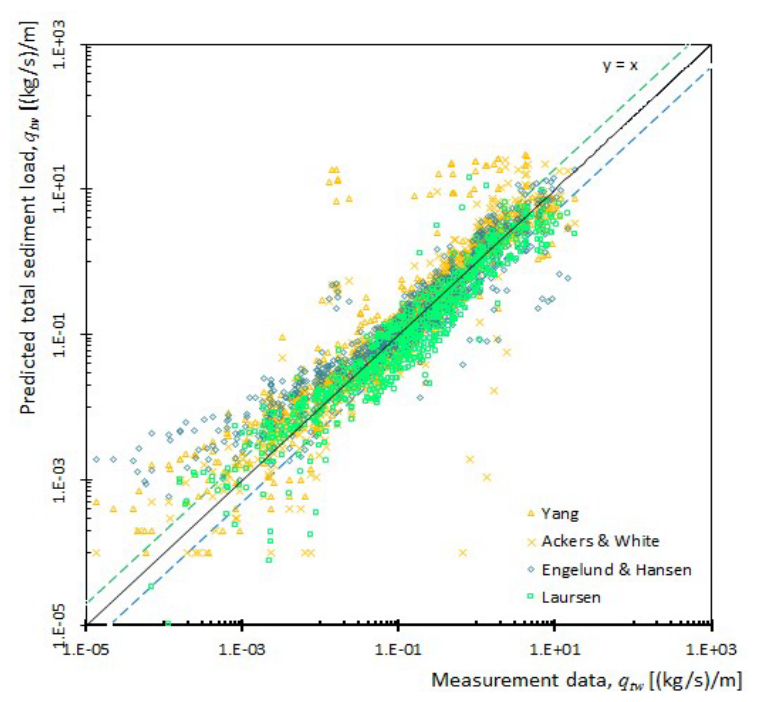

Fig. 3. Predicted against measured sediment load

\section{Back propagation Neural Network (BPNN)}

BPNN is a multi-layer device and it's able to overcome the complex non-linear problem since there are interconnections between neurons in algorithms. BPNN algorithm using delta rule generalization (Widrow-Hoff) applying the gradient descent method to minimize the total squared error at the output of the network and 
transferring non-linier derivative function [26]. The uniqueness of the backpropagation algorithm is able to map the input-output process through the feed forward and back forward. Input and output vectors are used to train the network until it can approach the appropriate function. BPNN has the built-in capability i.e. the adaptation of synaptic weights to changes in the surrounding environment through pattern recognition for adaptive information. The contextual information introduction will produce output that is natural since every neuron in a neural network may be potentially affected by the global activity against all the other neurons in the network. Furthermore, the analysis of neural network system performance smoothly degraded since the inherent fault tolerance. All ANN calculations in this study using a MATLAB program application because it has a very strong ability to solve problems in the form of a matrix calculation. The simple BPNN program used a command in the window command and create a program listing in the file editor. MATLAB has provided NNTool to train and test input data, targets and testing. Some types of neural network algorithms e.g. hebb, adaline, perceptron and probabilistic neural network.

Matrix that contains the input data and the target is used in the program listings, wherein the input matrix and the target should be in the format transpose. Before processing the data, a process of normalization and preprocessing conducted, so that the value of each data can be calculated with smaller values without losing the characteristics of the data itself. Hereinafter, BPNN network coding created to determine the number of hidden layers, the number of neutrons and the number of the output layer. Bipolar sigmoid activation function (tansig), unipolar (logsig) or function identity (purelin). In order to BPNN learning methods, the method used: trainlm.

The next step is to set the parameters that contain; the number of epoch (iteration) maximum learning $=1000$, minimum number of errors $=0.001$, the number of learning rate $=0.5$, the number of the epoch in which the appearance of the graph will be updated $=1000$, error and the amount of momentum $=0.7$. The next process is learning and evaluating the network output simulation performance, simulated with the target and training. Data need to be trained to determine which the most appropriate smoothing factor is. At the end of the training, the individual smoothing factors can be used as a sensitivity analysis tool: the bigger factor for a given input, the more important that the input is a model at least as far as the test set is concerned.

\section{Results and analysis}

From the calculation results using conventional sediment load estimation method, the data distribution almost coincides with the measurement data. The number of calculation results data that in the discrepancy ratio range was $71 \%, 75 \%, 67 \%$ and $69 \%$ respectively for Yang, Ackers and White, Engelund and Hansen method, and Laursen method. This results considered generally accepted since the discrepancies ratio has been above $60 \%$ (Fig. 2 and Fig. 3).

In the BPNN model, the input parameters that used in each simulation is in the same value, the differences is in the number of hidden layers. The results of simulations and calculated indicate that the performance of the BPNN model is good enough. However, from the distribution of the measurement data and the calculation results, it can be seen that the result of its spread still accumulate in the data center as seen in Fig. 4, 6 and 8. For more details, the result of the comparison expressed by a discrepancy ratio of $0.5-2$, can be seen in Fig. 5, 7, and 9. The percentage of the amount of the data that comes into the discrepancy ratio range are respectively $61 \%, 63 \%$, and $64 \%$ for 2,5 , and 10 hidden layers. The more hidden layers applied, the more accurate the results obtained. From these results it can be seen that modeling with BPNN suitable to predict the sediment load. The inaccuracies of the results caused by a large range between sediment load distribution data (target). Likewise, the range of each parameter input is also uneven. Correlation coefficient (R) training nearly to 1 , and mean square error (MSE) nearly to 0 . To obtain the good simulation results, consider the training, testing, validation and overall regression data were already close to 1 . The value of $\mathrm{R}$ for each hidden layer could be seen in table 3.

Table 3. Correlation coefficient (R)

\begin{tabular}{|c|c|c|c|c|}
\hline \multirow{2}{*}{$\begin{array}{c}\text { Hidden } \\
\text { layers }\end{array}$} & \multicolumn{4}{|c|}{ Correlation coefficient (R) } \\
\cline { 2 - 5 } & Training & Validation & Testing & All \\
\hline 2 & 0.961 & 0.943 & 0.936 & 0.953 \\
\hline 5 & 0.955 & 0.983 & 0.963 & 0.964 \\
\hline 10 & 0.963 & 0.971 & 0.972 & 0.965 \\
\hline
\end{tabular}

From table 3, it can be conclude that the number of hidden layers will influence the $\mathrm{R}$ value, although the differences is insignificant. When the data were already close to 1, then the simulation is finished and fittings are considered reliable. Conversely, if it is not, then the network should be retrained.

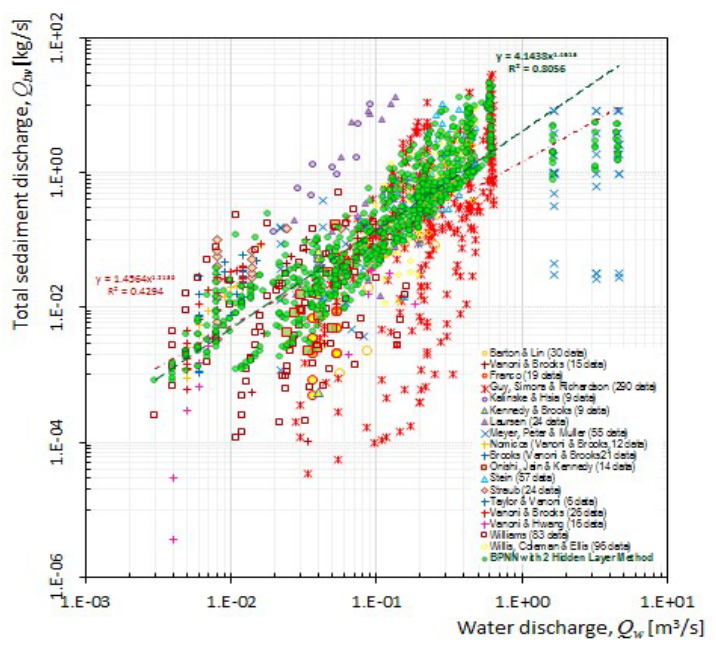

Fig. 4. The distribution of measurement data and calculation results with 2 hidden layers 


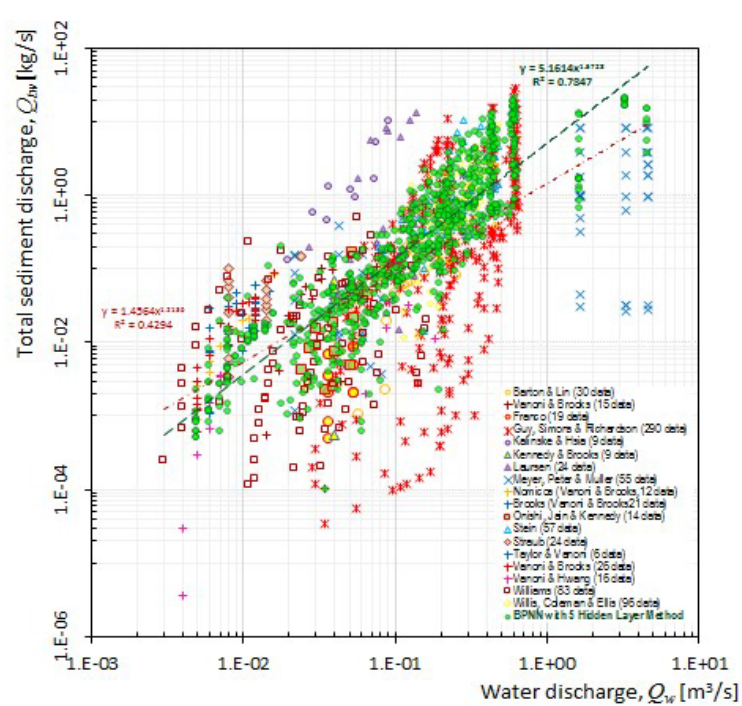

Fig. 6. The distribution of measurement data and calculation results with 5 hidden layers

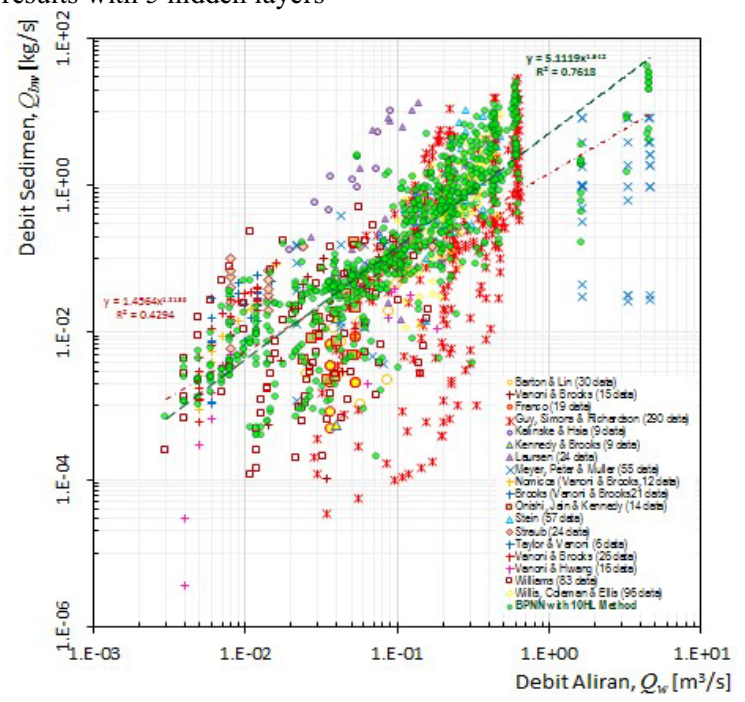

Fig. 8. The distribution of measurement data and calculation results with 10 hidden layers

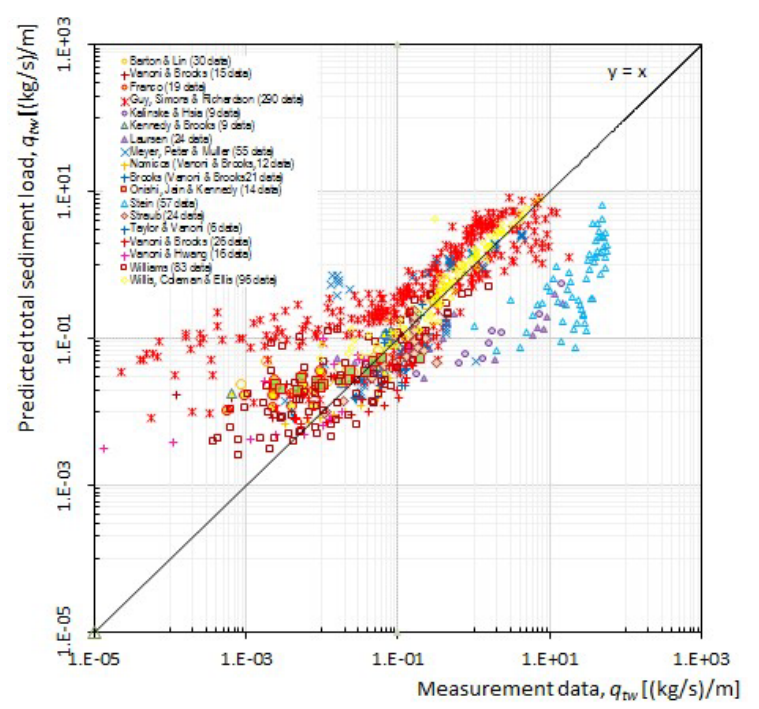

Fig. 5. Predicted against measured sediment load with 2 hidden layers

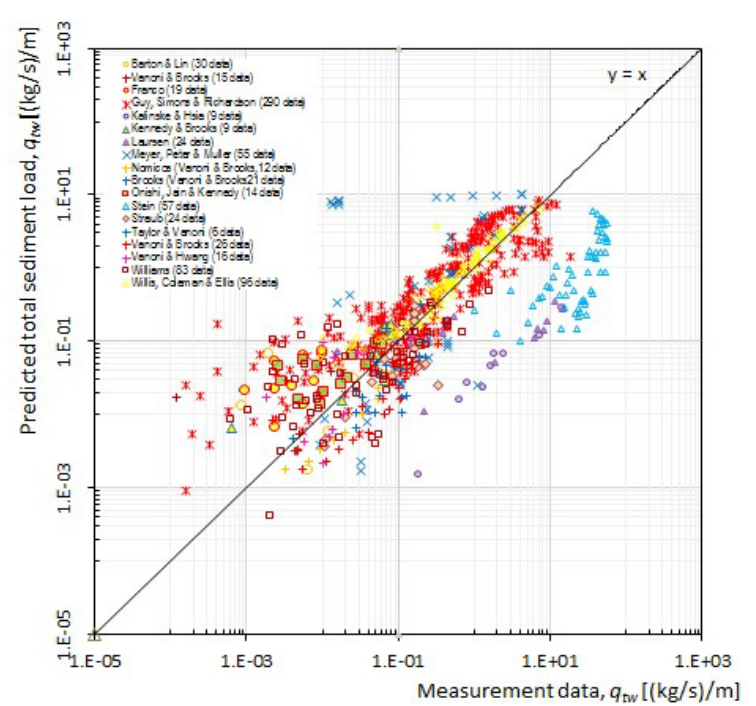

Fig. 7. Predicted against measured sediment load using BPNN with 5 hidden layers

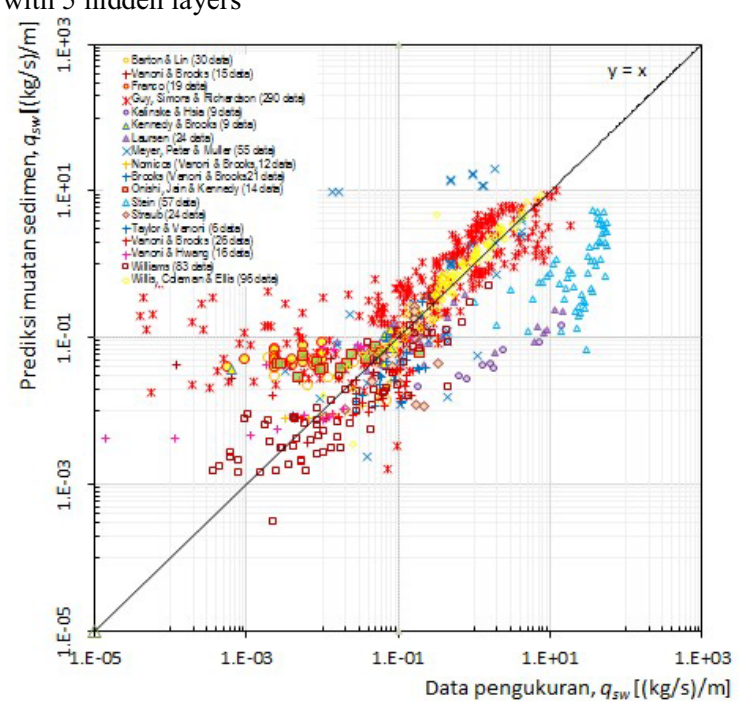

Fig. 9. Predicted against measured sediment load using BPNN with 10 hidden layers

\section{Conclusions}

The BPNN model can be used in the estimation of sediment load in rivers. The results obtained with the BPNN model is not satisfying compare with the results from conventional methods. Better outcomes will be obtained by increasing the number of hidden layers and variation parameters calculation contained in MATLAB models. The model predicted approximately $61 \%$ to $64 \%$ accuracy of the data for 2 to 10 hidden layers. This gives a clear robustness of the model for use in sediment prediction for rivers with different hydraulic and sediment characteristic.

The authors gratefully acknowledged Prof. Iwan Kridasantausa from Bandung Institute of Technology and Dr. Robert J. Kodoatie from Diponegoro University for the brief discussion and the support of secondary data. The authors would also gratefully Engineering Faculty, Sriwijaya University for the 
funding during this study period. Sincere thanks to Water Resources Development Center, Bandung Institute of Technology for the support during this publication process.

\section{References}

1. Haddadchi A, Dehghani AA., Journal of Hydrodynamics, Ser B. 24, p :145-51, 1 (2012)

2. Junaidah A, Nurashikin AK, Muhamad Syahreen Sa, Mohd Nasir T, Suhaimi A-T, Aminuddin A-G, Journal - The Institution of Engineers 69, 3 (2008).

3. Srinivasan VS, Cavalcante RG, Santos CA, Journal of Urban and Environmental Engineering (JUEE) 2, doi: 10.4090/juee. 2008. v2n1. 028032, (2009)

4. Habibi M, Sivakumar M, 11th Australasian Fluid Mechanics Conference Hobart, 1992.

5. Molinas A, Wu B., Journal of hydraulic research, 39, $p: 135-46,2$ (2001)

6. Kiat CC, Ghani AA, Wen L, 2nd International conference on managing river in the 21st centurySolutions toward sustainable river basins: Kuching, Sarawak, Malaysia, (2007)

7. Baosheng W, Van Maren D, Lingyun L. International Journal of Sediment Research. 23, p :283-98, 4 (2008)

8. Wang Y-G, Tian T, Journal of Hydrology 482, p :69$78,(2013)$

9. Van Griensven A, Popescu I, Abdelhamid M, Ndomba PM, Beevers L, Betrie GD., Physics and Chemistry of the Earth, Parts A/B/C 61, p :12-21, . (2013)

10. Talreja J, Global Research Analysis 2, 4 (2013)

11. Yeh T-h, Parker G., Computers \& Geosciences 53, p : 94-104, (2013)
12. Kodoatie RJ., Hidrolika Terapan, Andi Yogyakarta, p : $17-18,(2002)$

13. Kumar M. Evapotranspiration modeling using artificial neural networks, $\mathrm{PhD}$ thesis, Indian Institute of Technology, Kharagpur India. PhD thesis. 2003.

14. Sudheer K, Gosain A, Ramasastri K. A, Hydrological processes 16, $\mathrm{p}: 1325-1330,6$ (2002)

15. Adib A, Mahmoodi A., Journal of Civil Engineering, p : 1-11, doi : 10.1007/s12205-016-0444-2, (2016)

16. Makarynskyy O, Makarynska D, Rayson M, Langtry, Applied Soft Computing 35, p : 47-56, 2 (2015)

17. Atieh M, Mehltretter S, Gharabaghi B, Rudra R., Journal of Hydrology 531, p :95-107, 10 (2015)

18. Dai S, Lu X., Geomorphology 215, p :60-73, (2014)

19. Vafakhah M., Arabian Journal of Geosciences 6, p : 3-18, 8 (2013)

20. Haddadchi A, Movahedi N, Vahidi E, Omid MH, Dehghani AA., Journal of Hydrodynamics Ser B. 25, p :459-70, 3 (2013)

21. Lafdani EK, Nia AM, Ahmadi, Journal of Hydrology 478, p : 50-62, (2013)

22. Heng S, Suetsugi T., Journal of Water Resource and Protection 5, p : 111 -123, (2013)

23. Kisi O, Ozkan C, Akay B., Journal of Hydrology 428, p :94-103, (2012)

24. Çimen M., Hydrological Sciences Journal 53, p : 656-66, 3 (2008)

25. Kumar B., Hydrological Sciences Journal 57, p : 956-66, 5 (2012)

26. Nazari J, Ersoy OK. Implementation of backpropagation neural networks with MatLab: Purdue. 